\title{
Laser deposited Ni-based gradient coating with high wear-resistance on the surface of copper
}

\author{
Suiyuan Chen ${ }^{a}$, Guili Yin ${ }^{b}$, Ruixue Wang ${ }^{c}$, Jing Liang ${ }^{d}$, Changsheng Liu ${ }^{\mathrm{e}}$ \\ Key Laboratory for Anisotropy and Texture of Materials(Ministry of Education), School of Material \\ Science and Engineering, Northeastern University, Shenyang 110819, China \\ achensy@smm.neu.edu.cn, byinguili@163.com, ${ }^{c} 1730515703 @ q q . c o m,{ }^{d}$ liangj@atm.neu.edu.cn, \\ ecsliu@mail.neu.edu.cn
}

Keywords: laser deposition; gradient coating; metallurgical bond; Heat shock performance.

\begin{abstract}
A Ni-based alloy gradient coating with four layers of the different composition was produced on surface of $\mathrm{Cu}$ alloy substrate using YAG laser. The microstructure, anti-wear and anti-heat shock properties of the gradient coating were studied by means of analysis techniques. The results show that there are no cracks or pore on the surface and inside structure of the gradient coating. The main reinforcing phase of the Ni-based alloy gradient coating is $\mathrm{Cr}-\mathrm{Ni}-\mathrm{Fe}-\mathrm{C}$ and $\mathrm{Ni}_{4}(\mathrm{~W}, \mathrm{Mo})$. The micro-hardness of the gradient coating increase gradually with the direction from substrate to the surface, and micro-hardness of outermost layer reaches $834 \mathrm{HV}$, which is 8.3 times than that of $\mathrm{Cu}$-substrate. After eight heat shock tests at $750^{\circ} \mathrm{C}$, no crack was observed in the gradient coating and the gradient coating was still metallurgical bond with the substrate. This new Ni-based gradient coating has both high wear- resistance and anti-heat shock performance.
\end{abstract}

\section{Introduction}

With the development of continuous casting technology, it requires not only crystallizer of the good thermal conductivity, but also that of high corrosion resistance and wear resistance[1,2]. As steel production continues to increase, the copper alloy crystallizer consumed in continuous casting process is also much more than before. This is not only a cost increase of iron and still enterprise, but also a waste of precious copper resource. Therefore, it demands for higher quality of the surface of $\mathrm{Cu}$ alloy. However, because of the low resistance of it to abrasive wear, their application in engineering is limited under such high temperature conditions $\left(1500-1600^{\circ} \mathrm{C}\right)$. So, it demands urgently for improving the surface wear properties of $\mathrm{Cu}$ alloy crystallizer.

So far, the laser cladding Ni-based or Co-based alloy coating on the surface of the $\mathrm{Cu}$ alloy is a good process to increase wear resistant [3-6]. However, when the hard coating is cladded on the surface of $\mathrm{Cu}$ alloy, cracks and pores are hard to overcome in coating leading to relative low wear resistant[7-10]. In particular, the bonding strength of coating and substrate in high temperature has important effect on improving the service life of the coating. In order to overcome these problems and get good strength and toughness coating on the surface of $\mathrm{Cu}$ alloy crystallizer, in this paper, based on our previous studies[10], a new Ni-based alloy coating with four gradient layer in which strengthening elements such as C, W, Mo and Si distribute gradually is designed, and successfully prepared by pulsed laser. The surface morphology, micro-structure, phase compositing, micro-hardness, anti-wear, and anti-heat shock property of the gradient coating were studied experimentally by optical microscopy, X-ray diffraction, Scan electron microscopy, wear tester, and heat shock tester, respectively.

\section{Experimental Materials and Methods}

\section{Materials and methods of the samples preparation.}

The experimental substrate was cut from copper alloy $(\mathrm{Cu}: \mathrm{Cr}: \mathrm{P}=99.9: 0.07: 0.03)$ crystallizer plate. The dimensions of the samples are $20 \mathrm{~mm} \times 15 \mathrm{~mm} \times 10 \mathrm{~mm}$. Prior to cladding, copper alloy substrates were sandblasted and then cleaned in acetone. Then, for increasing the bond strength between coating 
and substrate, copper substrates will be dipped in $\mathrm{H}_{2} \mathrm{SO}_{4}$ (sulfuric acid)(70 80g/l) solution 0.5 1 minute to activate. After drying, its surface cleaned by using acetone. The four layers were synthesized with different compositions. The chemical compositions of the four layers are given in Table1. The content of the main elements $(\mathrm{Co}, \mathrm{Cr}, \mathrm{W}, \mathrm{Mo})$ were increased gradually from the first layer to the fourth layer for the purpose of forming metallurgical interface bond and hardness of the gradient coating increase gradually form the first layer to fourth layer.

The powders were mixed in ball milling about $12-15 \mathrm{~h}$ and then filtrated using a $250 \mathrm{\#}$ boult. The dope was mixed using 70\%powder and 30\% $\alpha$-cyanaloc acrylic resin adhesive, then the $0.5 \mathrm{~mm}$ thickness precoating coated on the surface of the samples, after drying in the room temperature by vacuumizing, they were used for laser post-treatment four layers, respectively. The laser treatment was performed by a YAG:laser with a wavelength of $1.06 \mu \mathrm{m}$ and a maximum average power of 400W. Optimized laser processing parameters: laser pulse width $3 \mathrm{~ms}$, current strength 200A, scanning speed $2.5 \mathrm{~mm} / \mathrm{s}$, beam size $0.48 \mathrm{~mm}$, overlap $30 \%$.

Table 1 Compositions of each layer of the coating (wt. \%)

\begin{tabular}{ccccccccccc}
\hline Element & $\mathrm{Ni}$ & $\mathrm{Co}$ & $\mathrm{Cr}$ & $\mathrm{Fe}$ & $\mathrm{W}$ & $\mathrm{Mo}$ & $\mathrm{Si}$ & $\mathrm{C}$ & $\mathrm{Al}$ & $\mathrm{Y}_{2} \mathrm{O}_{3}$ \\
\hline First layer & Bal. & 5 & 10 & 5 & 2 & 1 & 2 & 1 & 2 & 1 \\
Second layer & Bal. & 10 & 15 & 5 & 4 & 2 & 3 & 2 & 2 & 1 \\
Third layer & Bal. & 15 & 20 & 10 & 6 & 3 & 4 & 3 & 2 & 1 \\
Fourth layer & Bal. & 20 & 25 & 10 & 8 & 4 & 5 & 4 & 2 & 1 \\
\hline
\end{tabular}

\section{Experimental analysis.}

The microstructure and phase evolution of the gradient coating were characterized by optical microscopy (OM, OlympusGX71), X-ray diffraction XRD, scanning electron microscopy (SEM), and transmission electron microscopy (TEM). The microhardness was measured on the cross-section using Wilson Wdpert-401MVD Vickers with a load of $25 \mathrm{~g}$ for a loading time of 10 seconds. Tribological investigations were conducted with pin-on-disk apparatus under unlubricated conditions at room temperature. According to the ASTM G99-95 standard, the wear loss was calculated from the pin weigh change under wear testing. The average values of the wear loss from copper substrate and laser treated sample (more than three times replicate experiments) were compared. Heat shock test was done according to ISO 2819:1980. Equipment is a SKQ-36-11 Furnace, main parameter: Rating voltage is $220 \mathrm{v}$, Rating power is $3.6 \mathrm{kw}$, Rating Temperature is $1100^{\circ} \mathrm{C}$. Heat shock test temperature is $250^{\circ} \mathrm{C}$ and $750^{\circ} \mathrm{C}$, heat shock circles is form one to eight, heat preservation time is $30 \mathrm{~min}$.

\section{Results and discussion}

\section{Morphology and microstructure of the Ni-based alloy gradient coating.}

Fig . 1 shows the surface macro-images of the gradient coating by CCD camera (a) and stereomicroscope (b), Cross-section SEM image of the 4-layer gradient coating(c), and SEM micrograph of interface between the third and the forth layer of the gradient coating(d). Fig. 1(a) and (b) proved that the surface of gradient coating is complete and smooth, with the unique "ripple" morphology of pulsed laser. Fig. 1(c) indicated that there is no crack or pore on the section and inside structure of the gradient coating, and the interface between the coating and the substrate is an anomalistic curving shape. Fig. 1(d) shows the SEM micrograph of interface zone between the third and the forth layer of the gradient coating, its structure is also composed of flat grain, columnar grain and ultra-fine grain zone. The thickness of the flat grain zone is about $5 \mu \mathrm{m}$, the inside structure of the flat grain zone is more fine than that of the ultra-fine grain of the third layer. The reason is that its solidification speed was very rapidness due to it closed with third layer. Therefore, the microstructure of the four layer gradient coating is alternate distributing as flat grain, columnar grain and ultra-fine 
grain. The ultra-fine grain plays a fine-grain strengthening Ni-based alloy role. Furthermore, according to element design principle as shown in Table 1, due to content of $\mathrm{Cr}, \mathrm{W}$, C reinforced element in fourth layer is highest, more spherical second hard fine particles were produced in-situ in the fourth layer as shown in Fig. 1(d). These fine particles distributed dispersedly in the coating has a second-phase particles strengthening effect to the gradient coating.

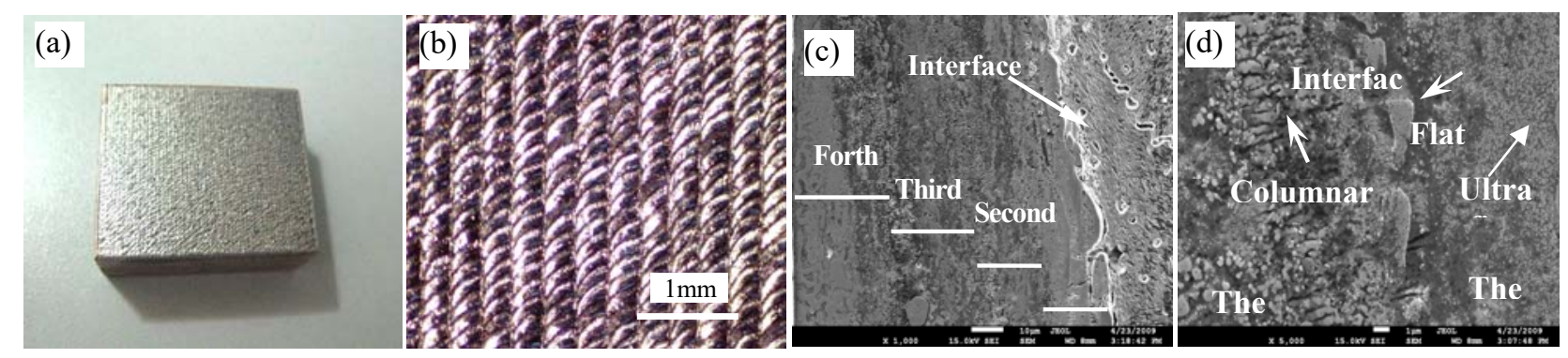

Fig. 1 Surface macro-images of the gradient coating by CCD camera (a), stereomicroscope (b), Cross-section SEM image of the 4-layer gradient coating(c), and SEM micrograph of interface between the third and the forth layer of the gradient coating(d).

XRD pattern of the surface of the Ni-based alloy four layer gradient coating is presented in Fig. 2. It reveals that the main phases are $\mathrm{Cr}-\mathrm{Ni}-\mathrm{Fe}-\mathrm{C}, \mathrm{CoCr}_{2}(\mathrm{Ni}, \mathrm{O})_{4}, \mathrm{Ni}_{4}(\mathrm{~W}, \mathrm{Mo})$ and $\mathrm{Cr}_{2} \mathrm{C}_{3}$ in Ni-based gradient coating. These composite hard phases can improve the hardness and wear resistance of the gradient coating.

Hardness and tribological performance of the gradient coating.

Fig. 3 shows the gradient variation of micro-hardness along the depth of the four layer gradient coating. The micro-hardness of the gradient coating increase gradually with the direction from first layer to the fourth layer. The micro-hardness of the fourth layer reaches $834 \mathrm{HV}$, which is 8.3 times than that of $\mathrm{Cu}$ alloy. On the one hand, this result is beneficial to the wear resistance of the gradient coating. On the other hand, the gradient distributing of the hardness proved that elements gradient design as shown in Table 1 was right. Namely, the content of the main reinforced elements such as Co, $\mathrm{Cr}, \mathrm{Fe}, \mathrm{W}, \mathrm{Mo}, \mathrm{Si}, \mathrm{C}$ increased gradually form the first layer to the fourth layer so that the number of reinforced hard phases particle also increased from the first layer to fourth layer.

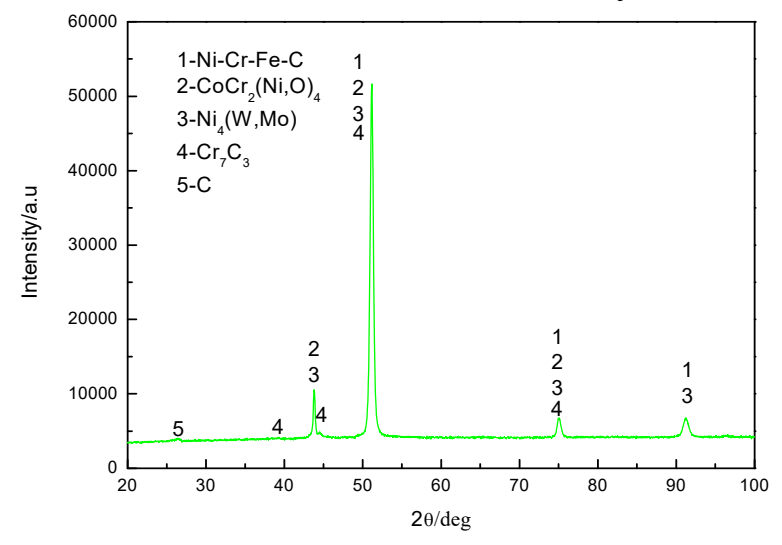

Fig. 2 XRD pattern of the Ni-based four layer gradient coating 


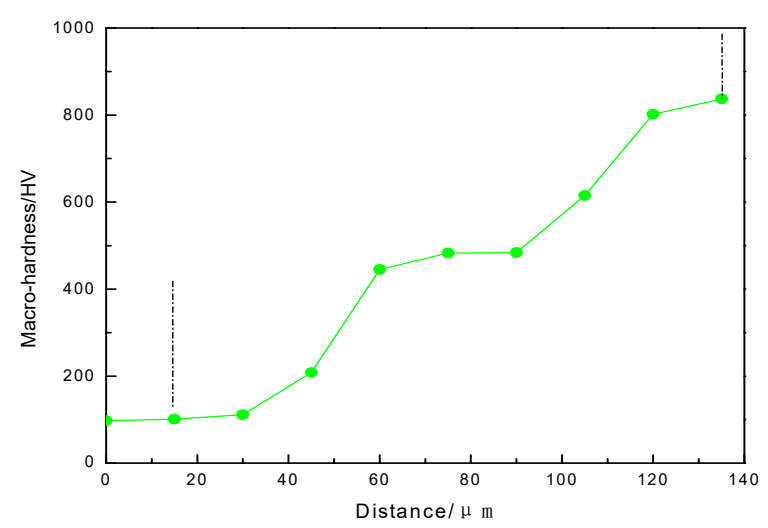

Fig. 3 The gradient variation of microhardness along the depth of the four layer gradient coating

Fig. 4 shows the wear loss and friction coefficient againsts wear time for the $\mathrm{Cu}$ substrate and the laser gradient coating. As can been seen from Fig. 4(a), along with prolong of wear time, the wear loss of the $\mathrm{Cu}$ alloy substrate increased obviously but that of the gradient coating increased slowly. Obviously, the wear loss volume removed of the gradient coating is much lower than the copper alloy substrate. The wear loss for the copper alloy substrate is about 8.4 times higher than the laser gradient coating sample at the wear time of $60 \mathrm{~min}$. Friction coefficient of the $\mathrm{Cu}$ alloy substrate and the laser gradient coating is up to steady volume after wear time of $45 \mathrm{~min}$, the friction coefficient of the laser gradient coating is about 0.21 , but that of the $\mathrm{Cu}$ alloy substrate is about 0.6 . So, the low friction coefficient of the gradient coating with four Ni-based alloy layers on the $\mathrm{Cu}$ alloy substrate produced by laser is another important factor of improving wear property.
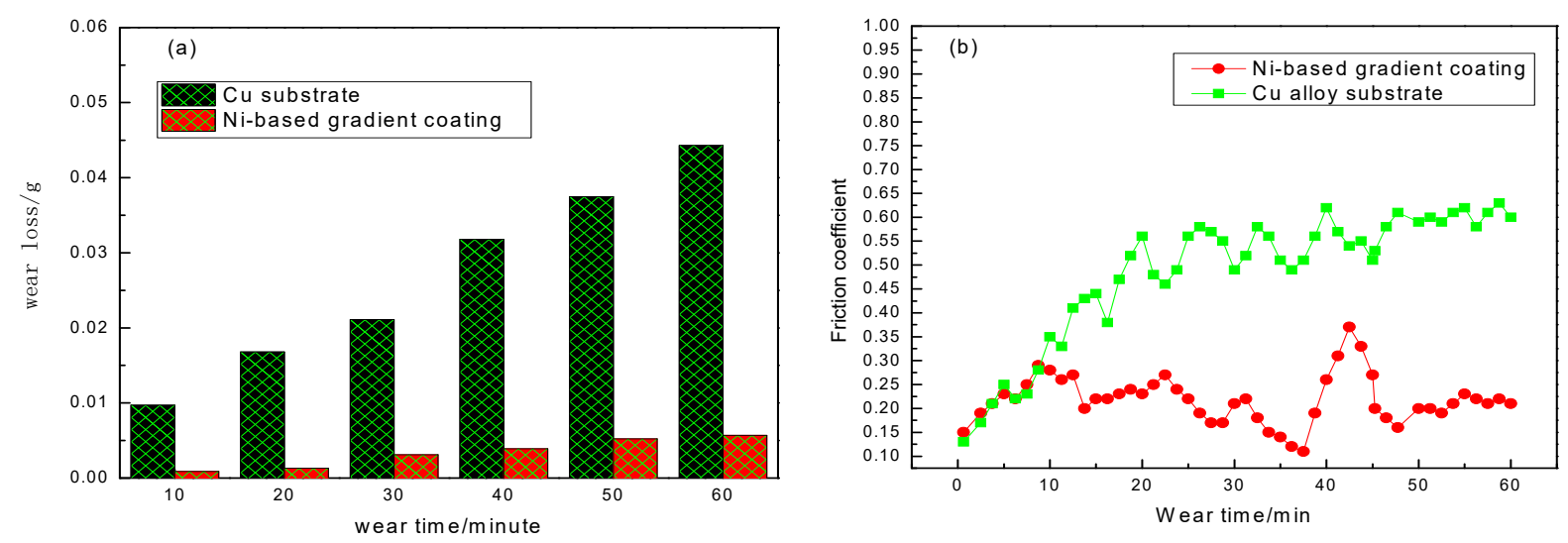

Fig. 4 Wear loss and friction coefficient againsts wear time in wear tests for the $\mathrm{Cu}$ substrate and the laser gradient coating(a)-wear loss; (b)-coefficient.

Heat shock measurements.

According to ISO 2819:1980 standard, the heat shock test method is as followings: 1) the furnace heated up to $250^{\circ} \mathrm{C}$ or $750^{\circ} \mathrm{C} ; 2$ ) the samples were set in furnace to heat preservation $30 \mathrm{~min}$ under air atmosphere condition; 3 ) the samples were took out from furnace and cooled in water $\left.\left(14^{\circ} \mathrm{C}\right) ; 4\right)$ the samples were observed if the coating had crazed or broken off from the $\mathrm{Cu}$ alloy substrate. Above process circled 8 times in this way.

Macro-images of the gradient coating sample heat shocked at $250^{\circ} \mathrm{C}$ and $750^{\circ} \mathrm{C}$ for eight circles is shown in Fig. 5. As can been seen form Fig. 5(a), after eight circles heat shocked, the appearance of the gradient coating did not happened obvious change besides the color. This proved that the Ni-based alloy gradient coating produced by laser can sufficiently meet adhesive strength of the ISO 2819:1980 standard requirement for coating of the common metal surface. Fig. 5(b) shows the macro-images of the gradient coating sample heat shocked at $750^{\circ} \mathrm{C}$. Comparing with the $250^{\circ} \mathrm{C}$ heat shocked test, after from first to eighth heat shocked, in addition to the color of the gradient coating surface changed from gray to dark gray due to oxidation happened under the high temperature air 
atmosphere condition, no cracks were observed in the coating surface and no piece of coating flaked off form the $\mathrm{Cu}$ alloy substrate, and the coating was still metallurgical bond with the substrate.

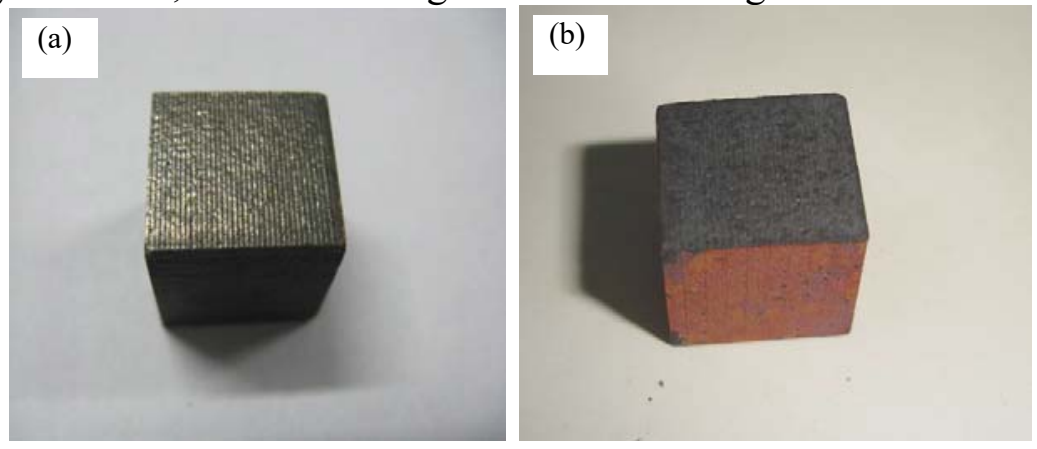

Fig. 5 Macro-images of the gradient coating samples heat shocked test: (a)-250 ${ }^{\circ} \mathrm{C}$ for eight circles; (b) $-750^{\circ} \mathrm{C}$ for eight circles.

Fig. 6 shows Cross-section OM morphology of the gradient coating heat shocked at $750^{\circ} \mathrm{C}$ for eight circles. The structure of the gradient coating is still fine and no heat shocked cracks and coating cracking are found in the cross-section, the interface between the gradient coating and $\mathrm{Cu}$ alloy substrate is also metallurgical link. This shows that the gradient coating with four Ni-based alloy layers possess excellent heat shock resistance toughness. Moreover, the thickness did not decrease obviously compared with that of the gradient coating without heat shocked, which indicates that high temperature oxidation erosion of the gradient coating is not serious.

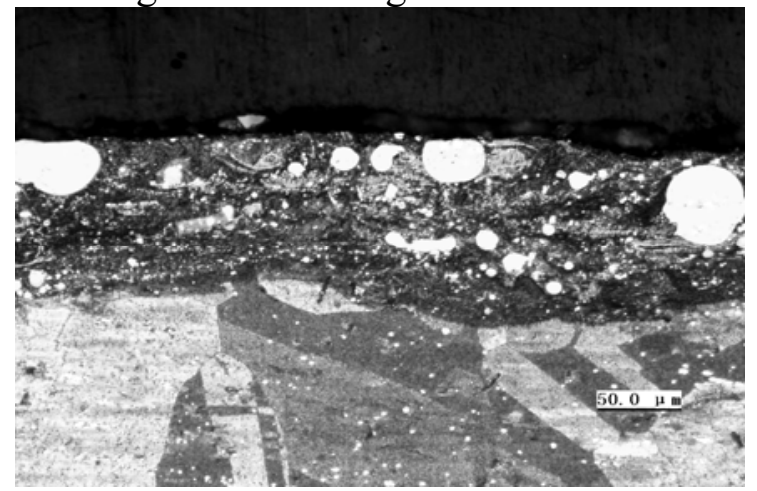

Fig. 6 Cross-section OM morphologies of the gradient coating heat shocked at $750^{\circ} \mathrm{C}$ for eight circles.

\section{Conclusions}

A Ni-based gradient coating made of four layers on a $\mathrm{Cu}$ alloy substrate has been prepared using YAG laser induced in-situ. There are no cracks or pores on the surface and inside structure of the coating, and the interface between the coating and the substrate is metallurgically bonded. The ultra-fine grain has a fine-grained strengthening effect on the coating. The main reinforced hard phases are $\mathrm{Cr}-\mathrm{Ni}-\mathrm{Fe}-\mathrm{C}, \mathrm{CoCr}_{2}(\mathrm{Ni}, \mathrm{O})_{4}, \mathrm{Ni}_{4}(\mathrm{~W}, \mathrm{Mo})$ and $\mathrm{Cr}_{2} \mathrm{C}_{3}$ in the gradient coating. The micro-hardness of the gradient coating increase gradually with the direction from substrate to the surface. The micro-hardness of outermost layer reaches $834 \mathrm{HV}$, which is 8.3 times than that of $\mathrm{Cu}$ alloy substrate. After eight heat shock tests at $750^{\circ} \mathrm{C}$, no crack was observed in the gradient coating and no piece of coating flaked off from the substrate, and the gradient coating was still metallurgically bonded with the substrate.

\section{Acknowledgements}

This work was financially supported by National Key Research Project(2016YFB1100201), National Natural Science Foundation of Liaoning United fund (U1508213), the Fundamental Research Funds for the Central Universities (N130810002), Science and Technology Plan Project of 
Liaoning Province (2014221006), Science and Technology Plan Project of Guangdong Province (2015B010122001).

\section{References}

[1] F. Liu, C. Liu, S. Chen, X. Tao, Y. Zhang, Optics and Lasers in Engineering, 48(2010) 792-799.

[2] H. Yan, J. Zhang, P. Zhang, Z. Yu, C. Li, P. Xu, Y. Lu, Surface \& Coatings Technology, 232(2013)362-369.

[3] Y. Zhang, M. Xi, L. Shi, Surface and Coatings Technology, 202(2008)5924-5932.

[4] F. Liu, C. Liu, S. Chen, X. Tao, Z. Xu, M. Wang, Surface and Coatings Technology, 201(2007)6332-6339.

[5] D. Zeng, C. Xie, M. Hu, A. Wang, W. Song, Surface and Coatings Technology, 200(2006)4065-4071.

[6] H. Yan, A. Wang, K. Xu, W. Wang, Z. Huang, Journal of Alloys and Compounds, 2010, 505(2): 645-653.

[7] D. Wang, Q. Hu, X. Zeng, Journal of Alloys and Compounds, 588(2014)502-508.

[8] M.J. Tobar, C. Alvarez, J.M. Amado, G. Rodriguez, A. Yanez, Surface and Coatings Technology, 200(2006)6313-6317.

[9] W. Song, J. Echigoya, B.D. Zhu, Surface and Coatings Technology, 126(2000)76-80.

[10] S. Li, Q. Hu, X. Zeng, S. Ji, Applied Surface Science, 240(2005)63-70. 